\title{
Oxygenated fuels properties and relationship with engine performance in port fuel injection engines.
}

\author{
Uriel Gonzalez*, Isaac Schifter. \\ Gerencia de Sustentabilidad Energética, \\ Instituto Mexicano del Petróleo, México \\ *Corresponding author: ugonzale@imp.mx
}

\begin{abstract}
Gasoline oxygenating agents (alcohols, ethers and a carbonate) were used to formulate gasoline at different oxygen contents up to 20 wt.\% and compared with commercial Premium gasoline.

The performance of each fuel was investigated in a port fuel injected, single cylinder, spark-ignited engine at different stages i.e. air fuel mixture preparation, combustion behavior and exhaust emissions. In all cases, the intake cooling effect (related mainly to fuel properties like latent heat of vaporization and Reid Vapor Pressure), shows an important relationship with engine performance and emissions, probably due to reductions in heat losses associated with decreases in charge temperature at compression stroke before ignition. This results was confirmed by means of vehicle FTP-75 test.

The high RVP promotes high intake manifold evaporation rate, and the high HoV is related to important cooling effect as the fuel absorbs heat during evaporation. If the fuel evaporates faster upstream intake valves, the advantages of high HoV as a way to reduce compression work and heat transfer fallen.

The quantification of the charge cooling effect was done by means of precision intake air temperature control and the instrumentation of a temperature downstream the injector at intake port and as close as possible to the intake valves.

The use of oxygenates reduce the hydrogen and carbon fuel contents as a result of fuel dilution. For a given level of oxygenation as lower is the molecular oxygen content in the additive, higher will be the fuel dilution.

For $10 \mathrm{wt} \%$ oxygen and more, fuel performance in port engines depends mainly on oxygenate contents and its relationship with HoV and RVP. For oxygenated gasolines, fuel sensitivity have a direct relationship with latent heat of vaporization, because charge cooling is one of the way alcohols increase RON. In the other hand, MON is almost insensible to high heat of vaporization, because the intake air is heated to $159 \mathrm{C}$ as a test requirement.
\end{abstract}

\section{Keywords}

Oxygenated gasoline, charge cooling, sensitivity, combustion, emissions

\section{Introduction}

Air pollution is becoming a serious problem in many urban cities of the world and it can have a severe effect on both health and the environment. All kind of internal combustion engines i.e. Spark Ignition (SI) and Compression Ignition $(\mathrm{Cl})$ are equally responsible for the emission as carbon monoxide (CO), nitrogen oxides (NOx), hydrocarbons $(\mathrm{HC})$, and particles pollutants [1].

Since $\mathrm{CO}_{2}$ emissions cause global warming, which is one of the major environmental problems today; it is assessed as a pollutant. In the occurrence of harmful substances in exhaust gas emissions, when type of fuel is taken into consideration, it is possible to lower these emissions by using different fuels. The use of oxygenated fuels in gasoline provides more oxygen in the combustion chamber, allows the use of higher compression ratios, and has the potential to reduce emissions [2].

Additives are integral part of today's fuel. Together with carefully formulated base fuel composition, they contribute to combustion efficiency and engine long life. They are chemicals, which are added in small quantities either to enhance fuel performance, or to correct a deficiency as desired by the current legislation. They can have surprisingly large effects even when added in little amount [3].

Replacing one or other additive means that the specifications and volume of the petroleum base fuels will have to be adapted in order to meet vapor pressure, octane numbers specification and other requirements for the entire gasoline blend sold at refilling stations. This in turn has an effect on the composition and on other specifications of the petroleum base fuels [4].

Although experimental studies have shown that oxygenated fuels burn cleaner than unleaded gasoline and produce lesser emission, there is limited information regarding the comparison among the oxygenated fuels as gasoline additive in spark-ignited engines. Among various renewable fuels, alcohols, such as ethanol, methanol, isobutanol, are the most popular fuels utilized in internal combustion engines.

Schifter et al. [5] used gasoline and gasoline-ethanol blends at the ratios of 0-20\% ethanol in a single cylinder engine, and showed that the combustion rate, efficiency and fuel consumption increased with the blend ratio. In addition, with the increasing of the ethanol ratio in the blend, the $\mathrm{HC}$ and $\mathrm{CO}$ emissions have decreased, but NOx emission has increased.

In order to satisfy the requirements for incorporation of fuel renewable compounds, in USA and other countries, the use of ethanol as an oxygenate agent was promoted. In places like Brazil, the use of ethanol as a fuel in Otto 
engines is more related to energetic diversification and economics reasons than to environmental aspects. From the comparison of the properties of fuels it is apparent than the amount of injected fuel has to be increased when alcohol is added to maintain the desired - typically stoichiometric - air to fuel ratio, which is necessary for the proper operation of the engine including its exhaust gas after treatment devices [6].

Jung et al [7] noted that light-duty vehicles with direct injection (DI) gasoline engine have been in commercial production since the late 1990's, and it is widely accepted that smaller displacement engines will replace larger ones as a way to meet higher fuel economy regulations. Turbocharged GDI engines can be more fuel-efficient and offer a performance benefit due to the higher volumetric efficiency at high load. Direct injection Otto engines are more efficient than port fuel injection ones mainly because the fuel is injected inside of the combustion chamber allowing different combustion modes in order to diminish emissions and fuel consumption. At the same time DI engines can have approximately one additional unit in compression ratio i.e.11.5:1 instead of 10.5:1 in port fuel injected engines.

Production ECUs (engine control units) generally have the capability of some degree of short-term and long-term adjustment of the fuel injection pulse width, intended to serve as a compensation for variations in the composition and fuel properties and in general working of the engine at any load, limited to full load. Such capacity has not, intended to cover, for example, a rather substantial increase in the fuel delivery rates when switching from gasoline to ethanol [6].

Currently, ethanol blended into gasoline at various concentrations is the most utilized alternative for spark ignition engines in order to incorporate non fossil components and for energetic diversification. Unfortunately, ethanol exhibits some negative attributes, such as significantly lower energy content, hygroscopic behavior and chemical toxicity [8]. In addition, broader consequences of fuel production need to be considered, as the current ethanol feedstock crops may compete with food production and be negatives in terms of cost-benefit.

One promising alternative to ethanol are ethers like ethyl-tert butyl ether (ETBE), used in Asia and some European regions not only as a manner to improve octane numbers in a cost-effective way, but also as an approach to reduce air pollution. The main advantages of ethers like ETBE over alcohols (mostly ethanol and methanol) are related with mixture stability, water tolerance, corrosion, and the achievement of low Reid Vapour Pressure (RVP) standards to reduce fugitive emissions [8].

In order to satisfy fuel environmental requirements in Europe, ETBE is used, because is derived from ethanol obtained from biomass and is considered as a biofuel, nevertheless, the required catalytic reaction to produce ETBE required isobutylene, usually obtained from fossil sources from either refining or from natural gas [9].

For an ethanol 30\%volume/70 \% gasoline blend, Wang et al. found in direct injection engines a the positive effect of charging cooling was reflected in the more advanced combustion phasing, higher engine thermal efficiency, and lower unburned gas temperature at Top Dead Center. The high heat of vaporization and low stoichiometric air/fuel ratio of ethanol blends both contributed to a better charge cooling effect [10].

Fuel spray properties play an important role in direct injection engines, nevertheless, in port injection engines, the air fuel mixture is prepared in the intake manifold, before intake valves with enough time to achieve uniform mixture between air and fuel. Nevertheless with the incorporation of high latent heat of vaporization compounds like alcohols in gasoline, the fuel properties change, modifying the temperature of the blend as the fuel gets evaporated.

The more often octane numbers used as a way to quantify the capacity of a fuel to avoid auto ignition and suppress engine knock, are Research Octane Number (RON) introduced in 1928 and the Motor Octane Number (MON). This properties are obtained by means of a machine named Cooperative Fuel Research (CFR) engine. The MON test is considered more aggressive than the RON test, i.e. the MON is lower than the RON.The main difference between the RON and MON methods are the engine regime and the ignition time. In general, MON can be more representative of high load conditions and have higher engine speed (900 rpm vs. $600 \mathrm{rpm}$ ) and a higher intake temperature of $149{ }^{\circ} \mathrm{C}$ downstream of the carburetor vs. $52{ }^{\circ} \mathrm{C}$ upstream of the carburetor in RON test. To accomplish manifold temperature in MON test uses heater, cancelling any effect associated with fuel heat of vaporization.

This research is focused in the determination of relationships between fuel formulation, engine performance and its exhaust emissions for different oxygenated gasolines, taking in to account base fuel composition, oxygenating level and agent, considering in deep physicochemical analysis, fuel oxygen contents form $3.5 \mathrm{wt} \%$ to $20 \mathrm{wt}$. $\%$ and more and three different functional groups (i.e. ethers, alcohols and one carbonate).

\author{
Material and methods \\ Test Fuels \\ A baseline fuel was formulated without oxygen content from refinery-typical blending streams. The inspection data \\ for the gasoline components was performed following American Society for Testing Materials procedures [11]. The \\ test fuels were prepared gravimetrically to the oxygen target value using a precision balance with a repeatability of \\ $0.001 \mathrm{~g}$. by "splashing" the oxygenate compound with the base gasoline following prescriptions reported by Pahl \\ and McNally [12]. In splash blending, the oxygenate compound is added to a conventional gasoline without much \\ consideration for the final properties of the fuel.
}

Further details on the properties, composition and main characteristics of the blends are reported in Table 1 


\begin{tabular}{|c|c|c|c|c|c|c|c|}
\hline Property - Fuel ID & 1 & 2 & 3 & 4 & 5 & 6 & Commercial \\
\hline Oxygenated compound & ETBE & $\mathrm{EtOH}$ & $\mathrm{EtOH}$ & DMC & $\mathrm{EtOH}$ & $\mathrm{MeOH}$ & MTBE \\
\hline Oxygen in gasoline, wt.\% & 3.5 & 3.5 & 10 & 20 & 20 & 20 & 1.8 \\
\hline Volume in gasoline, vol.\% & 22 & 9.4 & 27.1 & 29.2 & 55.5 & 38.1 & 9.7 \\
\hline Paraffins, wt.\% & 9.25 & 10.53 & 7.19 & 7.55 & 5.15 & 7.27 & 8.2 \\
\hline Isoparaffins, wt.\% & 29.61 & 33.71 & 22.98 & 23.91 & 16.33 & 23.03 & 48 \\
\hline Olefins, wt.\% & 6.62 & 7.44 & 4.89 & 5.51 & 3.77 & 5.31 & 8.20 \\
\hline Napthenes, wt.\% & 3.43 & 5.04 & 3.60 & 3.63 & 2.48 & 3.50 & 2.90 \\
\hline Aromatics, wt. $\%$ & 27.67 & 31.03 & 22.06 & 21.71 & 14.83 & 20.91 & 23.00 \\
\hline Specific gravity & 0.735 & 0.741 & 0.749 & 0.783 & 0.760 & 0.750 & 0.731 \\
\hline LHV, MJ/kg & 41.59 & 41.48 & 38.49 & 32.86 & 33.85 & 33.94 & 42.8 \\
\hline RVP, psi & 6.53 & 8.46 & 8.17 & 7.61 & 6.38 & 10.34 & 7.65 \\
\hline C, wt.\% & 82.5 & 82.3 & 73.7 & 68.2 & 66.2 & 66.2 & 86.2 \\
\hline $\mathrm{H}, \mathrm{wt} . \%$ & 13.7 & 13.6 & 13.1 & 9.9 & 12.6 & 12.1 & 11.8 \\
\hline $\mathrm{H} / \mathrm{C}, \mathrm{mol}$ & 2.0 & 2.0 & 2.1 & 1.7 & 2.6 & 2.3 & 1.9 \\
\hline Air-to-fuel ratio, wt./wt.\% & 14.17 & 14.2 & 12.53 & 10.70 & 11.33 & 11.23 & 14.15 \\
\hline RON & 94.6 & 94.0 & 101.9 & 98.0 & 121.8 & 109.0 & 97.0 \\
\hline MON & 84.3 & 83.0 & 87.0 & 89.2 & 87.2 & 86.4 & 87.0 \\
\hline $\mathrm{AKI},(\mathrm{RON}+\mathrm{MON}) / 2$ & 89.4 & 88.5 & 94.4 & 93.6 & 104.5 & 97.7 & 92.0 \\
\hline $\mathrm{HoV}, \mathrm{KJ} / \mathrm{kg}$ & 342 & 406 & 512 & 356 & 678 & 647 & 312 \\
\hline $\mathrm{IBP},{ }^{\circ} \mathrm{C}$ & 42.1 & 39.8 & 43.3 & 40.1 & 50.0 & 40.0 & 37.0 \\
\hline $\mathrm{T}_{10},{ }^{\circ} \mathrm{C}$ & 64.2 & 53.2 & 56.2 & 58.2 & 67.5 & 49.9 & 58.1 \\
\hline $\mathrm{T}_{50},{ }^{\circ} \mathrm{C}$ & 89.4 & 95.4 & 73.6 & 89.2 & 78.6 & 62.2 & 98.7 \\
\hline $\mathrm{T}_{90},{ }^{\circ} \mathrm{C}$ & 158.5 & 162.3 & 160.7 & 161.7 & 80.7 & 153.5 & 163.5 \\
\hline End point, ${ }^{\circ} \mathrm{C}$ & 208.9 & 211.6 & 211.8 & 207.8 & 174.1 & 205.1 & 205.3 \\
\hline
\end{tabular}

Table 1. Physical and chemical properties of the fuels

Single cylinder engine tests

The experiments were performed on an AVL 5401 SI single cylinder engine electronically controlled, capable of 25 $\mathrm{KW}$ at $6000 \mathrm{rpm}$. The engine load is absorbed by an asynchronous dynamometer controlling the engine speed with $\pm 1 \mathrm{rpm}$ accuracy. The supply system comprises an AVL-735C fuel temperature conditioner, and an AVL-735 consumption meter based on Coriolis principle.

The system utilizes a stand-alone fuel management system model brand General Engine Management Systems allowing to modify injection and spark ignition timing independently, and with an AVL-619 Indimeter in order to monitor and acquired the combustion related camera pressure information .

The crank angle position and combustion chamber pressure is monitored with a $0.1^{\circ}$ of turn resolution. The engine is controlled by AVL Puma Open 7.1 software and data acquisition, integrating the dynamometer, delivery systems, fuel conditioning, and measurement, as well as emissions analysis.

The load was selected as a partial load condition at mid-range speed to avoid the engine to become chocked during the inlet flow in the admission process at high speeds that may reduce the volumetric efficiency.

On the other hand, avoiding slow engine speeds prone to higher heat transfer through the walls, lowering the average combustion gas temperature and pressure, and reducing the work per cycle transferred to the piston. In Table 2, the main engine characteristics and operating conditions are showed. 


\begin{tabular}{lc}
\hline \hline Type & spark ignition, double overhead cam, 4V \\
Bore and stroke & $86 \mathrm{~mm}$ \\
Displacement & $0.5 \mathrm{~L}$ \\
Compression ratio & $10.5: 1$ \\
Fuel delivery & port fuel injection \\
Regime & $2,400 \mathrm{rpm}$ \\
IMEP & $6.5 \mathrm{Bar}$ \\
Spark advance & $12.42{ }^{\circ} \mathrm{BTDC}$ \\
Admitted air mass & $24.5 \mathrm{~kg} / \mathrm{hr}$ \\
Intake air pressure & $1035 \mathrm{mBar}$ \\
Intake air temperature & $48^{\circ} \mathrm{C}$ \\
Intake air humidity & $<5 \%$ \\
fuel temperature & $40^{\circ} \mathrm{C}$ \\
Coolant temperature & $90^{\circ} \mathrm{C}$ \\
Oil temperature & $95^{\circ} \mathrm{C}$ \\
\hline
\end{tabular}

Table 2. Engine characteristics and operating conditions

During test development with different fuels, the indicated mean effective pressure (IMEP) was keeping as constant as possible and the fuel was adjusted to keep the stoichiometric air-fuel ratio and engine load, therefore the IMEP was kept almost constant $( \pm 0.5 \%)$.

In order to compare fuels with different oxygenate contents, it becomes necessary the use of a dimensionless parameter that allows comparisons at the same air-fuel ratio for every fuel composition. This is accomplished by Brettschneider equation [13] which provides the lambda value based on exhaust emissions provided by AVL-CEB II gas analyser and fuel composition, including $\mathrm{H} / \mathrm{C}$ and $\mathrm{O} / \mathrm{C}$ ratios.

To insure the reproducibility of the measurements for different fuels and operating conditions, experimental data were averaged over consecutive 100 cycles, and its dispersion analysed by means of descriptive statistics common methods. The mean and the median value of each data set was compared in order to determine the nature of distribution obtained, considering for each variable a $95 \%$ statistical confidence level.

Chassis dynamometer tests

We employed the FTP-75 light-duty driving cycle in order to test the emissions of a Nissan TIIDA 2013 gasoline vehicle, designed to comply with United States Tier 1 limits of emissions when new (CO, $2.1 \mathrm{~g} \mathrm{~km}^{-1}$; non-methane hydrocarbons (NMHC), $0.156 \mathrm{~g} \mathrm{~km}^{-1}$; NOx, $0.25 \mathrm{~g} \mathrm{~km}^{-1}$ ). The vehicle was equipped with air-fuel ratio (AFR) control systems mainly supported in lambda sensor signal.

The FTP test is used in México and another countries to certify the emissions of new vehicles. This cycle has three separate phases: a cold-start (505-second) phase known as Bag 1, a hot-transient (864-second) phase known as Bag 2 , and a hot-start (505-second) phase known as Bag 3. In each phase, an aliquoted sample diluted with air by means of a constant volume sampler (CVS) is collected in one different bag, and analyzed individually.

The total test time for the FTP-75 is 1874 seconds, the average speed is $34.1 \mathrm{~km} \mathrm{~h}^{-1}$, and the travel distance is 17.8 $\mathrm{km}$ [14]. Before the tests, the vehicle was conditioned on the road over a course designed to simulate a portion of the FTP-75 cycle in terms of typical speeds, as well as number of stops, and a sequence of engine off and idles were performed.

The experiments were carried out in our facilities on a standardized dynamometer system. Emission gas samples were collected into Tedlar bags during each phase of the FTP-75 cycle, and the vehicles operated on a Horiba-ECDM-48 single-roll electric dynamometer coupled to a constant-volume sampler unit (Horiba CVS-45).

Total HCs, NMHCs, CO, NOx, and $\mathrm{CO}_{2}$ concentrations were measured using a Horiba MEXA-9200D-gas analyzer system [14]. The test program was examined using the statistical methods described in previous works [14].

The criterion to determine whether a repeat-test was necessary was performed when FTP emissions ratio between the larger value divided by the smaller value, was greater than 1.17 for THC, 1.33 for CO, and 1.40 for NOx [15]. The absolute excess cold start emissions is defined as the additional emission value obtained under cold conditions compared to the emission value that could have been recorded for the same period (cycle) under hot conditions. The absolute excess cold start emissions can be calculated by subtraction of the hot soak Bag 3 emissions from the cold start Bag 1. 


\section{Results and discussion}

\section{About Fuel Properties}

As oxygen content in the fuel increases, the fuel carbon and hydrogen contents diminish as a result of fuel dilution. i.e. for a given oxygenating level, the effect is inversely proportional to the molecular oxygen content in the additive, in spite of oxygenant functional group. The fuel added with DMC have the lowest hydrogen contents, associated mainly to the DMC lowest $\mathrm{H} / \mathrm{C}$ ratio respect to the other oxygenates

Fuel composition depends mainly of oxygenation level (how much oxygen by weight have the gasoline) and oxygenated compound added (how much oxygen have the oxygenated molecule) In figure 1 . Are presented the experimental results for low heating value for fuels with different levels of oxygenation by means of different oxygenated compounds i.e. ethers (ETBE, MTBE), alcohols (EtOH, $\mathrm{MeOH}, \mathrm{IBuOH})$ and DMC. The labels identify the fuel included in the test matrix in Table 1. In spite of the fuel composition, base gasoline used, or oxygenate agent, the LHV reduce linearly with weight oxygen content. The R squared of the linear adjust showed is 0.99 . The abundance of samples with $3.5 \mathrm{wt}$ \% oxygen is related to Mexico actual specification. This result have relevance because make easy to stablish similar test conditions for very different test fuels. I.e. if the admitted air mass and the Lambda value (air-fuel ratio) is constant, the results can be compared back-to back for every fuel.

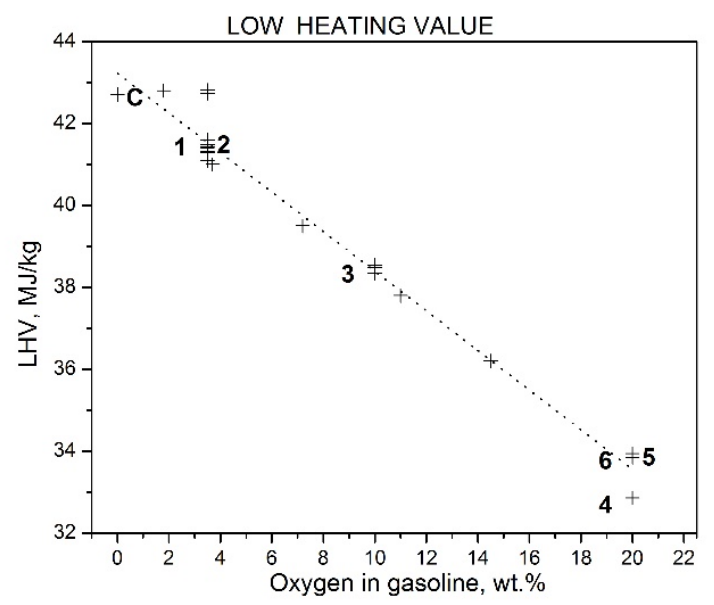

Figure 1. LHV as a function of fuel oxygen content

In figure 2, shows a survey of different fuels tested in single cylinder engine at similar conditions to the ones described in Table 2. In abscissa, the heat of vaporization and in ordinate, the Reid Vapor Pressure. The charge cooling (i.e. intake air temperature upstream injector minus blend temperature at intake port is included as a thermal scale i.e. cold colors for the highest cooling effect. The stream cooling in the manifold depends strongly on RVP i.e. the fuel mass evaporated in the intake manifold depend on how fast the fuel evaporates before intake valves. HoV determines how much energy is absorbed by the air-fuel blend during evaporation. i.e. fuel with alcohols have the highest HoV and the ones with ethers (ETBE and MTBE) and carbonate (DMC) the lowest ones, as shown the labels that identifies the oxygenated used in each fuel. The number in the left side of the points identifies the fuel on Table 1. As the HoV increases and RVP diminishes, the conditions to take advantage of fuel cooling effect are better, because more fuel is getting evaporated inside of combustion chamber, reducing the compression work and heat transfer to engine refrigerant circuit. This result suggest intake manifold insulation, geometries to reduce the mixture residence time in the manifold and use of low RVP fuel with high HoV (added with alcohols) as a strategies to improve engine efficiency. In accordance with this criteria, fuel 5 can be identified as the best fuel in the matrix. 


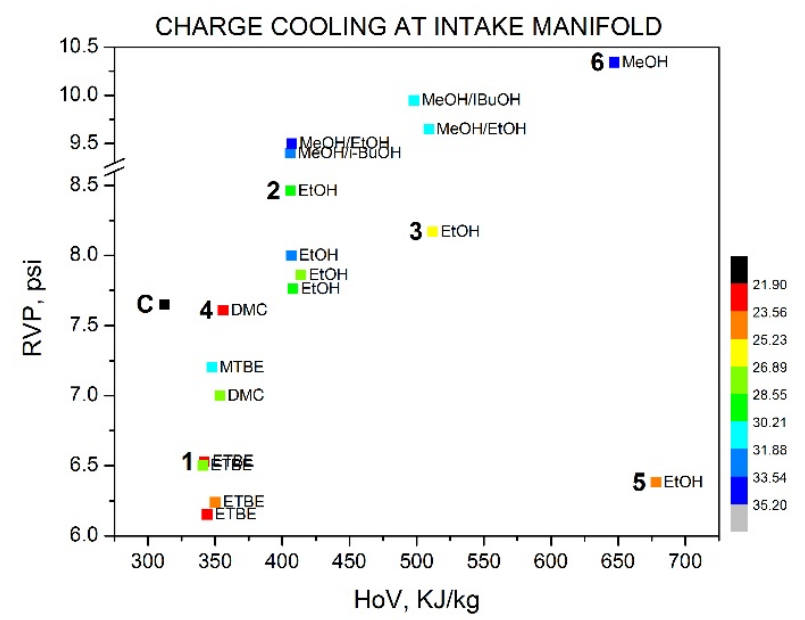

Figure 2. RVP and HoV Charge cooling for selected fuels. Cooling effect in thermal scale

In figure 3 the fuel sensitivity vs. HoV is presented for different fuels, including the ones from matrix 1 . In spite of fuel formulation or base fuel octane index, the fuel sensitivity strongly depends on HoV and this is governed by oxygen content and oxygenant functional group (ethers and carbonates < alcohols). As mentioned before, in MON test, the air-fuel blend must be heated to 149 Centigrade, hiding all the fuel improvement in knock resistance associated with charge cooling effect. This result is highly relevant, in actual port and direct injection engines the manufacturers try to avoid intake manifold high temperature reducing the heat transfer from the engine head and from the surroundings using nonmetallic materials ad specific geometries, contributing to the low specificity of MON test as a way to avoid knocking for in use and new vehicles.

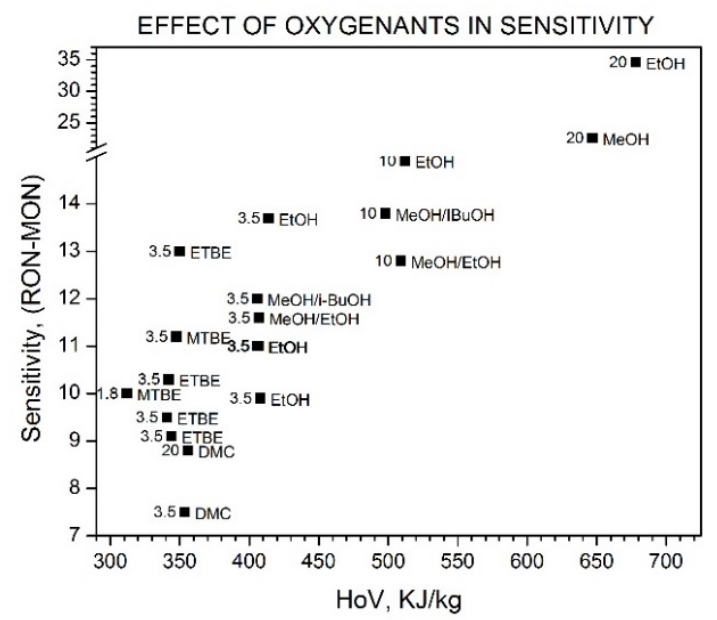

Figure 3.Fuel sensitivity as a function of HoV. In labels, oxygen content in wt.\% and oxygenant

In figure 4 , for $50 \%$ mass burned fraction crank angle i.e. combustion centre of gravity, the ignition advance was optimized for commercial fuel, formulated with MTBE, then, all the fuels was tested with the same ignition spark angle in order to detect changes related to speed of combustion. For the fuels formulated with low oxygenation level (3.5 wt.\%), the combustion delays respect to the Commercial fuel. Never the less, for fuels formulated with alcohols at high concentrations, were latent heat of vaporization depends on oxygen contents, the combustion gets faster. The fuel formulated with DMC (low HoV) the combustion was the one with the slowest combustion. 


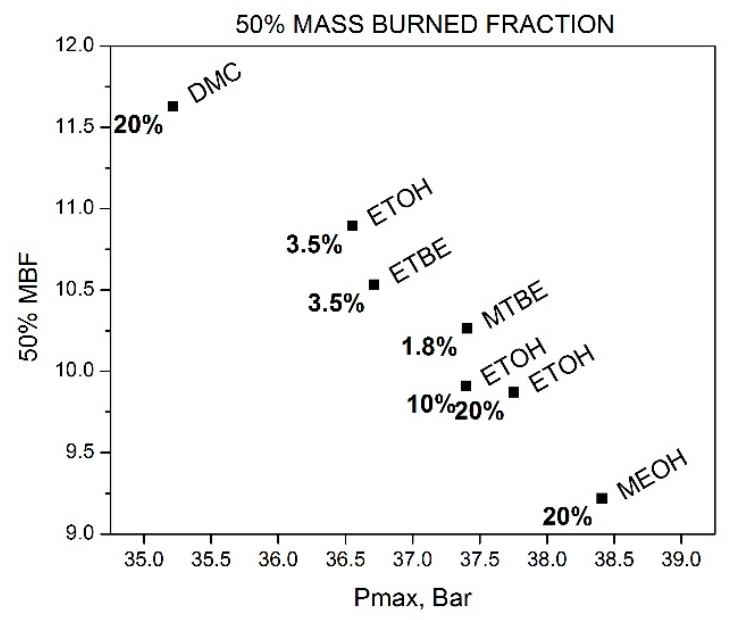

Figure 4.Combustion centre of gravity for tested Fuels. In labels, oxygen content in wt.\%

The fuel properties-engine experimental results matrix was examined by Factor analysis. In Figure 5, Factor 1 explains $47.4 \%$ of the total variability and Factor 2 explains $18.7 \%$ of total variability. Several gasoline and engine variables were included with high factor loadings, indicating stronger associations. In this analysis, also are included different baseline gasoline formulations.

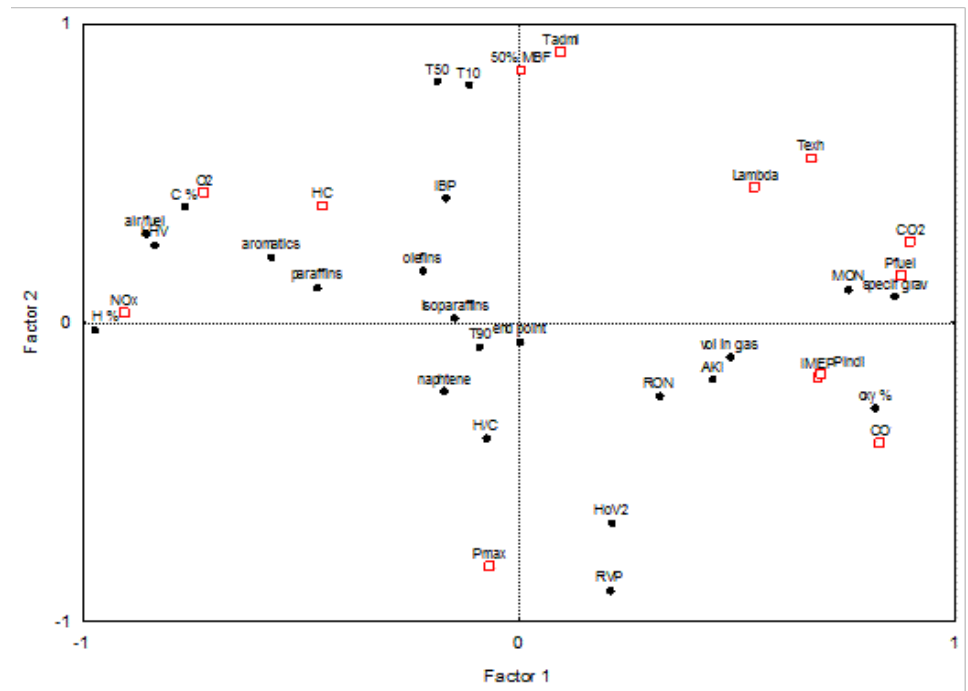

Figure 5. Factor analysis for tested fuels. Fuel properties in black points and engine results in red squares

In accordance with this analysis, the fuel oxygen content (oxy\%) and specific gravity (spec grav) are positively associated with $\mathrm{CO}$ and $\mathrm{CO} 2$ emissions and negatively associated with NOx. Properties like LHV, fuel hydrogen wt.\% $(\mathrm{H} \%)$ are positively associated with NOX emissions. NOX and $\mathrm{CO} 2$ are negatively correlated between them (i.e. inversely proportional).

Again in Figure 5, in ordinate axis Factor 2 (which explains $18.7 \%$ of total variability) is presented. Properties related to fuel evaporation like ASTM D-86 temperatures for $10 \%$ and $50 \%$ distillation (T10, T50) and air fuel temperature downstream injector (Tadmi), have a proportional association with $50 \%$ MBF and inversely relationship with Pmax. At the same time, Heat of vaporization and RVP (related to fuel evaporation to) correlates directly with Pmax and inversely with $50 \%$ MBF. Factor analysis clearly confirm the importance of properties related with fuel evaporation in combustion centre of gravity.

Factors like, T90, final boiling point, isoparaffins and naphtenic hydrocarbons contents or base gasoline show marginal effects in engine operation or emissions. About base fuel composition, only hydrogen, carbon and aromatics contents looks relevant and this properties are more related to fuel dilution than to base fuel formulation. Finally, in order to test results in full vehicle following the FTP-75 chassis dynamometer cycle, blends with 0, 10, 20, 45 and 85 wt.\% ethanol was prepared by splash blend from the same base fuel. The vehicle was instrumented 
for data acquisition form ECU, including throttle position (TPS), engine rpm and load, and intake air and coolant temperatures. In figure 8 , the pondered emissions results are showed.

The weighted results shows emissions below the United States Tier 1 limits for 0,10 and 20 wt. \% ethanol in fuel, Nevertheless, for $45 \%$ and $85 \%$, the NOx emissions are above the limit of $0.25 \mathrm{~g} / \mathrm{Km}$, as a result of enleanment. In spite of the used fuel, the hydrocarbon emissions are one order of magnitude higher for bag 1 (cold start) than form bag 3 (hot start). As ethanol contents increases in the fuel, the CO emissions gets lower, never the less, hydrocarbons increases, showing opposite effect to the enleanment, probably as a result of wall quenching phenomena related to lower cylinder wall temperature (because high $\mathrm{HoV}$ ) specially during the first seconds since cold start.

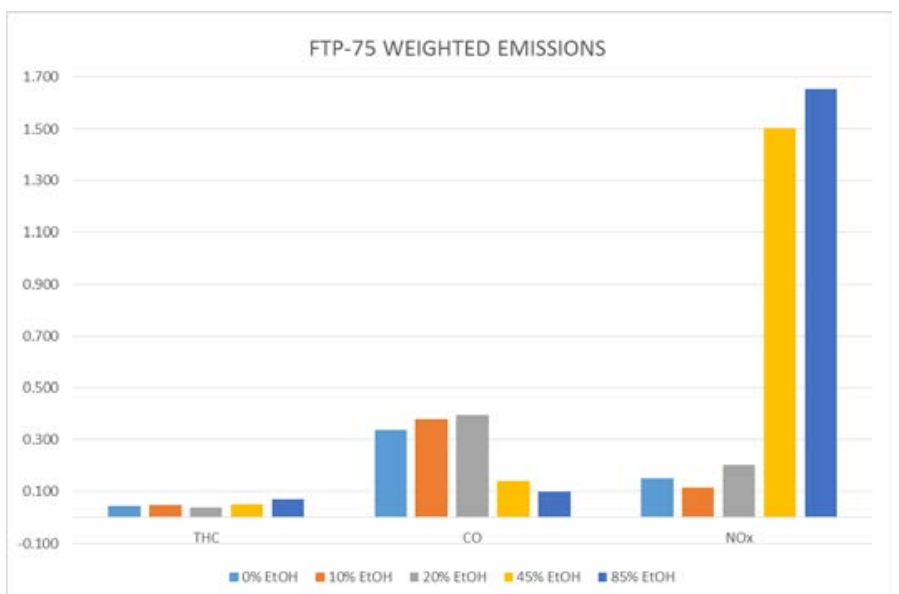

Figure 8. FTP 75 weighted emissions for tested fuels up to $85 \%$ ethanol

In figure 9, in the right side, the evolution of engine speed during the first minute since cold start is showed, is possible to see some erratic operation for fuel with $85 \% \mathrm{EtOH}$ during the first 25 seconds, the fuel with $45 \% \mathrm{EtOH}$ show higher rpm at idle than the rest of the fuels. Next, in the right side, the coolant temperature evolution during the first 505 seconds is presented. For the coolant (left side), at the end of the 505 test, the difference between the highest temperature (fuel with $10 \% \mathrm{EtOH}$ ) and the lowest one (fuel with $85 \% \mathrm{EtOH}$ ) are 6 Centigrade, opposite, the intake air lowest temperature corresponds to fuel with $10 \% \mathrm{EtOH}$ and the highest to the one with $85 \% \mathrm{EtOH}$. Clearly this performance is connected with RVP and HoV. As the HoV gets higher i.e. more $\mathrm{EtOH}$, the engine gets cooled because the heat is absorbed during fuel evaporation and delays the coolant temperature increase. In the other hand, the fuels with 10 and 20wt.\% EtOH have higher RVP than the gasoline without EtOH and gets evaporated early in the intake manifold, reducing air temperature. As the ethanol content increases and the RVP increases to, the fuel delays to evaporate absorbing heat from the combustion chamber and not from the intake manifold, increasing the intake air temperature.
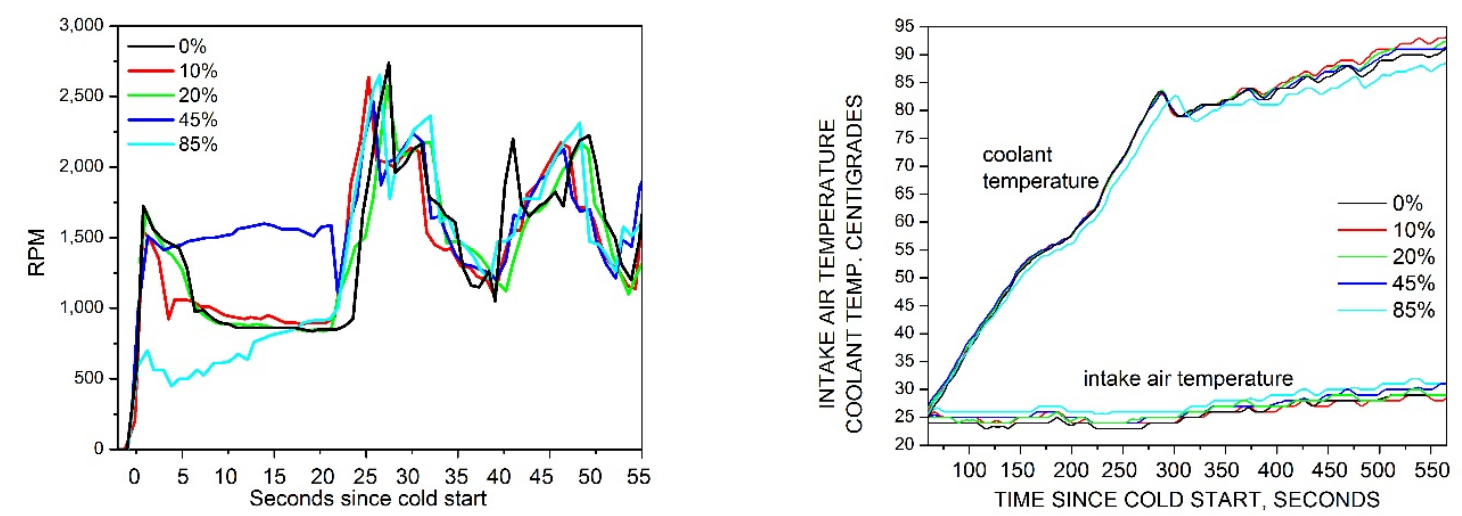

Figure 9. RPM during the first minute of FTP 75 (right side). Intake air temperature and coolant during the first 550 seconds in the same cycle (left side). 


\section{Conclusions}

Relationships between fuel formulation, engine performance and emissions for port fuel injection engines was identified for gasolines with oxygen contents up to $20 \mathrm{wt} . \%$.

The use of oxygenates reduce the hydrogen and carbon fuel contents as a result of fuel dilution. For a given level of oxygenation as lower is the molecular oxygen content in the additive, higher will be the fuel dilution. The calorific power diminish linearly with oxygen content by weight, in spite of the oxygenant and base fuel used.

As higher is the heat of vaporization i.e. higher alcohol content, higher is the charge cooling effect, but in order to take advantage of the high $\mathrm{HoV}$ as a way to reduce the compression work and the heat losses before ignition, a low Reid vapour pressure is necessary in order to absorb more heat from the air inside of combustion chamber and less form the intake manifold.

For oxygenated gasolines, fuel sensitivity have a direct relationship with latent heat of vaporization, because charge cooling effect is one of the way alcohols increase RON. In the other hand, MON is almost insensible to high heat of vaporization, because the intake air is heated to $159 \mathrm{C}$ as a test requirement.

Highly oxygenated fuels with alcohols (i.e. 10wt.\% oxygen and more) burn faster than other fuels and this effect is related to alcohols high heat of vaporization. In counterpart, highly oxygenated fuels with low HoV burns slow. For low oxygenated fuels (3.5 wt.\%) no matter which oxygenant is used, the combustion speed is similar and depends more on fuel base formulation.

Evaporative fuel properties like T10, T50, HoV and RVP have important effects in combustion centre of gravity. Factors like, T90, final boiling point, isoparaffins and naphthenic contents or base gasoline formulation, have marginal effects in highly oxygenated fuel performance and exhaust emissions.

As the ethanol content increases in the fuel, some enleanment take place, producing high NOx emissions. During the FTP-75 cold start phase, with 10wt.\% ethanol fuel, the intake air temperature in lower than for baseline fuel without ethanol as a result of cooling charge at intake manifold associated with high RVP. As the ethanol contents increases, the intake air temperature increases again as a result of RVP reduction, decreasing cooling charge at the manifold. For $85 \%$ ethanol, the intake air temperature is 3 centigrade higher than for $10 \%$. At the end of FTP75 cold start phase the coolant temperature is 6 centigrade lower for $85 \%$ ethanol fuel than for the reference without ethanol.

\section{References}

[1] Varol,Y., Öner, C., Öztop, H. F., Altun, S., 2014, Comparison of Methanol, Ethanol, or n-Butanol Blending with Unleaded Gasoline on Exhaust Emissions of an SI Engine, Energy Sources, Part A, 36,pp 938-948.

[2]. Balki,M.K., Sayin,C., Canakci, M., 2014, The effect of different alcohol fuels on the performance, emission and combustion characteristics of a gasoline engine, Fuel ,pp.901-906.

[3]. Balaji,D., Govindarajan,P., Venkatesan,J., 2010, Influence of isobutanol blend in spark ignition engine Performance and emissions operated with gasoline and Ethanol, International Journal of Engineering Science and Technology, 2 (7), pp. 28592868

[4] Croezen, H.J., Kampman, B.E., van de Vreede, G., Sevenster, M.N., 2007, ETBE and ethanol: A comparison of CO2-savings CE publication number 07.4226.42. Delf, NE.

http://www.cedelft.eu/publicatie/etbe and ethanol\%3A a comparison of co2 savings/716.

[5] Schifter, I., Diaz, L., Rodriguez, R., Gómez, J.P., Gonzalez, U., 2011. Combustion and emissions behavior for ethanol-gasoline blends in a single cylinder engine. Fuel, 90 pp. 3586-3592.

[6] Fenkl, M., Pechout, M., Vojtisek, M, N-butanol and isobutanol as alternatives to gasoline: Comparison of port fuel injector characteristics, 2016, EPJ Web of Conferences 114, 02021.DOI 10.1051/epjconf/201611402021.

[7]. Jung, H., Shelby, M., Newman, C., Stein, R., 2013. Effect of ethanol on part load thermal efficiency and $\mathrm{CO}_{2}$ emissions of $\mathrm{SI}$ engines. SAE Int. J. Engines, 6 pp. 456-469.

[8]. Jones, B., Mead, G., Steevens, P., 2008, The Effects of E20 on Plastic Automotive Fuel System Components, Tech. Rep. 20082/21/2008, Minnesota Center for Automotive Research,

[9]. Rodríguez-Antón, L.M., Hernández-Campos, M., Sanz-Pérez, F. 2013, Experimental determination of some physical properties of gasoline, ethanol and ETBE blends. Fuel, 112, pp 178-

[10]. Wang, C., Janssen, A., Prakash, A., Cracknell, R., Xu, H,(2017), Splash blended ethanol in a spark ignition engine - Effect of RON, octane sensitivity and charge cooling. Fuel 196 pp. 21-31 84.

[11].American Society for Testing Materials, Standard Specification for Spark-Ignition Engine Fuel, D-4814-01a. PA, USA 2001.

[12]. Pahl R.H and McNally MJ. Fuel blending and analysis for the auto/oil air quality improvement research program; Paper No. 902098; Society of Automotive Engineers; Warrendale, PA. USA 1990.

[13]. Brettschneider, J., 1997, Extension of the equation for calculation of the air-fuel equivalence ratio. SAE technical paper 972989, DOI: 10.4271/972989.

[14]. Schifter, I., González, U., González-Macías, C., 2016, Effects of ethanol, ethyl-tert-butyl ether and dimethyl-carbonate blends with gasoline on SI engine. Fuel, 183, pp.253-261

[15]. Painter, L., Rutherford, J.A. (1992). Statistical design and analysis methods for the auto/oil air quality research program. In Auto/Oil Quality Improvement Research Program; SAE Technical Paper No. 920319 PA, USA. Society of Automotive Engineers 